\title{
A arte de governar os dados em tempos de COVID- 19
}

\author{
BARBARA GONÇALVES MORAES \\ Universidade Federal do Rio de Janeiro, Rio de Janeiro, Rio de Janeiro, Brasil \\ brbgmoraes@gmail.com
}

DOI 10.11606/issn.2316-9133.v29isuplp124-134

resumo Os números que têm narrado a difusão do COVID-19 no Brasil se tornaram parte do nosso cotidiano através da publicação diária de dados sobre a pandemia. Esses dados sugerem algumas reflexões sobre a política e a técnica implicadas a um só tempo nas práticas governamentais e nas práticas científicas. Este ensaio busca estender as reflexões do meu trabalho de mestrado sobre práticas de conhecimento estatais a um momento em que as estatísticas se tornaram uma das formas que os discursos oficiais, biomédicos e midiáticos têm assumido. O que os dados sobre a COVID-19 nos informam a respeito dos modos de ver e produzir conhecimento das ciências de governo? Como ficam as relações entre Ciência e Estado quando personalidades do mundo da política passam a produzir narrativas divergentes a respeito de questões de saúde pública?

palavras-chave Técnica e política. Práticas de conhecimento. Ciências de governo. Antropologia do Estado. Antropologia da política.

\section{The art of governing data in times of COVID-19}

abstract The numbers that have been daily narrating the spread of COVID-19 in Brazil suggest some thoughts on the politics and techniques involved at the same time on governmental and scientific practices. This essay seeks to extend the issues pointed out in my master's work on the state's practices of knowledge to a moment when statistics have become part of our daily life through the publication of data regarding the pandemic crisis. How do the relations between Science and State stand when personalities from the world of politics produce their own narratives about public health issues? What can these data tell us about the ways of seeing and producing knowledge by the sciences of government?

Keywords Technique and politics. Practices of knowledge; Sciences of government. Anthropology of the State. Anthropology of politics. 


\section{El arte de gobernar a los datos en el tiempo del COVID-19}

resumen Los números que han narrado la propagación de COVID-19 en Brasil se han convertido en parte de nuestra vida cotidiana por medio de la publicación de datos sobre la pandemia. Estos datos sugieren algunas reflexiones sobre la política y la técnica implicadas en un momento dado en las prácticas gubernamentales y las prácticas científicas. Este ensayo busca extender las reflexiones de mi trabajo de maestría sobre las prácticas de conocimiento del estado a un tiempo en que las estadísticas se han convertido en una de las formas que los discursos oficiales, biomédicos y mediáticos han tomado. ¿Qué nos informan los datos del COVID-19 sobre las formas de ver y producir el conocimiento de las ciencias gubernamentales? ¿Qué pasa con las relaciones entre la ciencia y el Estado cuando personalidades del mundo de la política comienzan a producir narraciones divergentes sobre temas de salud pública?

palabras-clave Técnica y política. Prácticas de conocimiento. Ciencias del gobierno. Antropología del Estado. Antropología de la política

\section{Introdução}

Eu havia acabado de chegar ao programa de pós-graduação em antropologia e logo o isolamento se fez necessário. Foram semanas difíceis esperando pelo resultado da bolsa sem perspectivas muito certas de quais seriam os critérios da CAPES depois da portaria 34, que corta recursos fundamentais dos programas de pós-graduação de diversas áreas no Brasil. Até então pandemia e cortes da CAPES não tinham qualquer relação evidente entre si. Foi no caminhar lento do isolamento social, entre recomendações da OMS e recomendações de ministros e presidente, que certas disputas em torno de discursos biomédicos e discursos político-econômicos pareceram estender as reflexões que vinha desenvolvendo no meu trabalho de mestrado para longe do que havia sido definido como o "campo" da pesquisa. Nela, busco compreender as práticas de conhecimento associadas às ciências de governo a partir de um laboratório de inovação de governo de Brasília, o qual acompanhei em suas primeiras formações durante o trabalho de campo que realizei na Escola Nacional de Administração Pública (ENAP) em 2016. Neste espaço no qual as práticas governamentais estão sendo repensadas à luz das ciências comportamentais, das ciências sociais, dos estudos da comunicação e do design, os limites entre a técnica e a política estão sendo constantemente negociados.

Mas é também nos discursos públicos, nas práticas legislativas e judiciárias, e no desenvolvimento de dados, que a produção de uma ciência de governo se faz. Este ensaio busca ampliar as reflexões do meu trabalho de mestrado a um momento em que a produção de dados se tornou parte do nosso cotidiano através da publicação diária de estatísticas a respeito da COVID-19. Essas estatísticas, produzidas pelo Ministério da Saúde e secretarias 
municipais e estaduais de saúde, nos atualizam não apenas dos casos e óbitos relacionados à pandemia, mas de certos modos de ver, pensar e produzir conhecimento. Nesse sentido, procuro refletir sobre as implicações da produção de dados nas relações entre Ciência e Estado, e então compreender de que modo os dados nos informam a respeito de certas práticas de conhecimento mobilizadas pelas ciências de governo.

\section{Ciência e Estado}

Os conflitos em torno das condições mais adequadas para se enfrentar um cenário de pandemia evidenciam algumas das articulações e tensões existentes entre Ciência e Estado que os colocam em posições bastante distintas neste momento. A despeito das recomendações de especialistas da Organização Mundial da Saúde em relação às medidas mais adequadas para enfrentar o cenário de crise, acompanhamos ao pronunciamento de figuras do poder executivo que lançavam dúvida a respeito da veracidade e da letalidade do vírus, desafiando as medidas de isolamento social. Já em uma fase mais avançada da pandemia, novas controvérsias em torno dos tratamentos com a hidroxicloroquina e a nitazoxanida figuraram no centro das disputas entre presidente e seus ministros e importantes institutos de pesquisa brasileiros, como a Fiocruz. Através de notas técnicas e ofícios administrativos, o Ministério da Saúde pressionava os laboratórios e institutos para que indicassem tratamentos que ainda se encontravam em fase de testes ou que, segundo a comunidade médico-científica, já haviam comprovado não terem sido eficazes.

Essas disputas colocam em evidência aquilo que Stengers (2002) argumentou ser uma prática constitutiva do próprio saber: a alegação de que um outro produz ficções é parte fundamental da instituição de alguns fatos como legítimos. A essas disputas e alianças no campo dos saberes, Stengers chamou de uma política constitutiva das práticas de conhecimento, isto é, o esforço recorrente em se diferenciar de outros modos de ver e pensar, conferindo a alguns certa autoridade técnica sobre um assunto. Nesse sentido, Ciência e Estado compartilham um mesmo estatuto procedimental, este que confere um acesso privilegiado à verdade através de técnicas e tecnologias de conhecimento. A noção de práticas de conhecimento que mobilizo neste artigo é, então, inspirada pela descrição de Stengers (2002) da política do conhecimento que constitui tanto as práticas científicas quanto as práticas governamentais.

Diante dos esforços recentes de diversos pesquisadores em articular Ciência e Estado através de práticas de produção de conhecimento, e da centralidade da figura do especialista (MORAWSKA; RIBEIRO, 2018), como ficam essas relações quando personalidades do mundo da política passam a produzir narrativas divergentes a respeito de questões de saúde pública, como é o caso dos conflitos envolvendo o presidente Jair Bolsonaro e os profissionais da saúde? Ou quando o poder executivo declara uma guerra à ciência, cortando 
recursos fundamentais de pesquisa em diversas áreas do conhecimento em meio a uma pandemia?

Em um curso ministrado no Collège de France em 1978, Foucault (2008) apresentou a maquinaria de um novo sistema de poder, orientado para a gestão da população através de ferramentas estatísticas e de uma ciência de governo capaz de manipular e produzir dados em grande escala. Não à toa, somos bombardeados todos os dias com estatísticas sobre a pandemia produzidas e publicadas pelo Ministério da Saúde em um site desenvolvido apenas para a contagem dos casos e óbitos por COVID-19 ${ }^{1}$. A produção de dados, isto é, a contagem e as previsões sobre a vida da população, mas também a contagem dos mortos, nos dizem muito a respeito da eficácia ou não das políticas governamentais ${ }^{2}$, e por isso, há de se tomar cuidado com as curvas projetadas em um gráfico. Os números nos contam mais sobre as tecnologias de governo em jogo do que de fato sobre a vida daqueles que estão sendo contados.

Como nos mostram os esforços de Hacking (1991) em sua retomada histórica da produção estatística, a avalanche dos números em meados do século XIX, com a criação dos censos e das análises quantitativas, se torna uma forma de discurso bastante difundida, que pretende governar a incerteza, gerir as probabilidades. As estatísticas criam, então, uma maquinaria burocrática que está intimamente relacionada às classificações de normalidade e patologias, normas e desvios. Justamente por isso, recebe na França o nome de "ciência moral" antes de se tornar a ciência estatística. Ela não apenas pretende explicar os fenômenos do presente, como predizer as variações futuras, isto é, domesticar as chances, governar os fenômenos. No Brasil, as estatísticas também se articularam desde sua formação à maquinaria governamental. Aqui, em 1851-1852, a primeira tentativa de realização de um censo pelo Conselho de Ministros culminou em revoltas populares contra as medidas censitárias e de registro do governo imperial (SENRA, 2011). Mais tarde, com a criação da Sociedade Estatística do Brasil, um plano estatístico é traçado com protagonismo de marqueses e viscondes envolvidos na administração pública e o primeiro Censo Geral acontece em 1872. A história das estatísticas no Brasil nos conta também uma história sobre o Estado, mas mais do que retomar os processos sócio-históricos de consolidação das práticas estatísticas e das formações estatais, interessa a este artigo explorar as narrativas criadas pelas próprias práticas de produção de dados, bem como entender a que outras narrativas se articula para se propagar enquanto forma de discurso oficial.

É esse imbricamento entre ferramentas de conhecimento e ferramentas políticas que torna a produção científica uma grande ameaça para o Estado, sobretudo as ciências humanas, cujo objeto por vezes se confunde com o objeto sobre o qual incidem as políticas de governo. Esse objeto comum é identificado por Nikolas Rose (2006) como sendo, em

\footnotetext{
${ }^{1}$ https://covid.saude.gov.br/

${ }^{2}$ Uso eficácia como um parâmetro de avaliação próprio das políticas governamentais.
} 
certo momento, "o social", sobre o qual incidem os conhecimentos das ciências sociais e as práticas do Welfare State (Estado de bem-estar social), mas em "liberalismos avançados", isto é, em formas contemporâneas do modelo de democracia liberal ${ }^{3}$, esse objeto seriam as liberdades, vontades, comportamentos ou comunidades, também objetos de certas linhas das ciências comportamentais, da comunicação social, das ciências sociais e de outras áreas. Essa é uma explicação possível, por exemplo, para a presença de métodos tão familiares às ciências sociais nas práticas do laboratório de inovação em governo de Brasília, como é o caso do "design etnográfico", técnica emprestada da antropologia e usada para fins muito distintos daqueles planejado pelos teóricos da etnografia.

É justamente porque esses objetos só tomam forma através da produção de conhecimento, uma vez que são efeitos de nossas práticas e não existem antes delas, que é preciso lembrar, como disse Jean Segata (2020) em um texto recente sobre as escalas da pandemia do coronavírus, que esses números que compõem as estatísticas são antes pessoas com trajetórias muito distintas, corpos que há muito tempo têm sido negligenciados pelas políticas estatais. Afinal, quando se legisla sobre a vida, a morte de alguns é também deliberada. Mortes de corpos negros, mulheres, idosos, indígenas, travestis e transexuais, corpos de lésbicas e gays, mas também de outros corpos, os corpos que nos contam histórias do nosso passado colonial, escravocrata, corpos como o Museu Nacional, passíveis de apagamento pelas chamas de um incêndio que nos diz muito sobre as escolhas de investimento do Estado.

Trato as estatísticas neste ensaio como um procedimento através do qual pensam e atuam as ciências de governo, e chamo de ciências de governo aquelas áreas de produção de conhecimento que estão interessadas propriamente na arte de governar, mas que não se restringe a elas. A arte de governar é elaborada e reelaborada em microescala por diversas instituições e não apenas pelos empreendimentos estatais, e é essa capacidade microescalar, microscópica, de se imiscuir na vida e de se articular com outras formas de produção de conhecimento, que faz das práticas de governo tão poderosas e perigosas.

\section{As estatísticas como prática de conhecimento}

O que a estatísticas nos dizem a respeito dos modos de ver e atuar das ciências de governo?

\footnotetext{
3 Essas categorias de "welfare state" e "liberalismo avançado" operam como conjunto de técnicas e tecnologias de governo que se articulam de diferentes formas em escala local (ONG; COLLIER, 2005). Sobretudo em países cujo passado colonial ainda ressoa em uma série de valores e práticas, como é o caso do Brasil, a hibridização local desses modelos globais é bastante distinta da forma como essa interação acontece em outros lugares. Um dos propósitos desse artigo é descrever como essa noção de governo pelo cálculo - que caracterizaria o que alguns autores entendem por técnicas neoliberais de governo - se parece com aquela operacionalizada na produção de dados sobre a COVID-19.
} 
Primeiro, que operam por classificações que homogenizam os dados em certas categorias: ora os mortos são contados por município, ora por idade, ora por predisposição ao vírus. A este procedimento poderíamos chamar de um modo aglomerador, já que evitar as aglomerações não têm sido um problema para as estatísticas em tempos de COVID-19. O problema da contagem dos mortos lembra as técnicas de contagem dos meninos mortos em uma política estadual de redução de homicídios no estado do Pernambuco, no qual o êxito do programa dependeu de uma série de escolhas burocráticas de classificação que pretendiam conter as duplicações das mortes nos relatórios (MORAWSKA, 2018). Por outro lado, o luto das mães, irmãs, amigos e tias se multiplicavam através das memórias dos meninos mortos. A escolha por certas classificações na organização aglomeradora dos dados, nos diz, então, sobre como uma vida deve ser contada. O modelo é censitário: um corpo, um sexo, uma raça, um município, uma morte. Trata-se, como disse Stengers (2002, p. 197), de "construir os critérios de uma medida legítima, que permita decidir o modo de determinação daquele que, legitimamente, poderá falar por mais de um".

Também pensam as ciências de governo através do procedimento contabilístico, isto é, a prática de transformar questões populacionais em problemas econômicos. Mais do que isso, em equacionar esses problemas em termos de gastos e investimentos. O discurso político-econômico, no entanto, varia a depender do público para quem se apresentam os dados. Na portaria 34 da CAPES, a redistribuição das bolsas de pós-graduação e o contingenciamento de bolsas estão ligados aos gastos do Estado com os programas. O mesmo se poderia dizer dos debates na Câmara a respeito da Reforma da Previdência desde a PEC 287 de 2016, que tem sido sustentada sob a alegação de um rombo nas contas da Seguridade Social. Nas conferências com os investidores, no entanto, a contabilidade se torna outra: a promessa de aprovação da reforma atrai investimentos. A ideia é retomar credibilidade para garantir boas avaliações de risco no mercado e não sofrer impactos econômicos tão grandes ${ }^{4}$. Isso significa falar em termos de investimento e não de gastos, e de produzir, para isso, boas estatísticas para as políticas governamentais de combate à COVID-19.

Se um dado é um dado, e por isso dispõe de certa neutralidade científica ou imparcialidade técnica, como explicar que um mesmo dado seja apresentado ora como gasto, ora como investimento, e que produza a um só tempo condições tão onerosas para uma parcela da população e avaliações tão positivas no mercado para outras?

A técnica implicada na produção de dados é vista como isenta de modulações políticas, esterilizada de possíveis disputas e afetações. Isso não quer dizer, é claro, que essas estatísticas não devam ser produzidas, mas que elas não são, afinal, imparciais. Elas se inserem em uma dupla perspectiva política: aquela que entendemos como sendo própria do

\footnotetext{
4 “Ministro diz que aprovação da Reforma da Previdência já atrai investidores”. Fonte: Agência Brasil. Página visitada em 24.04.2020.
} 
mundo da política, isto é, da política representativa e institucional, mas também aquela política constitutiva das práticas de conhecimento que disputam no campo dos saberes quem pode falar sobre o mundo e o que pode ser dito a respeito dele a partir de dados técnicos.

Os atravessamentos e disputas que modulam os dados, transformam também o mundo sobre o qual eles falam. Esse poderia ser um terceiro modo de operar das ciências de governo, um modo prático-teórico no qual os dados se transformam muito rapidamente em programas de ação de governo e os programas engendram cada vez mais dados. Conhecimento e prática se implicam de modo que os dados contribuem para a formação das realidades que estão descrevendo e não apenas as observam (CALLON, 2006). Esse é um aspecto das práticas estatais a que Bourdieu (2012) já nos chamava atenção ao falar do potencial das categorias oficiais em alterar as próprias experiências materiais (a relação doxahabitus). Mais recentemente, a noção de performatividade que aparece nos trabalhos de Callon (2006) e em alguns dos Science and Technology Studies, tem nos ajudado a pensar como as ciências operam a partir de relações entre modelos formais e artefatos técnicos que corporificam esses modelos, de modo que as experiências reais são profundamente afetadas ou mesmo produzidas por modelos científicos e suas ferramentas, como é o caso das estatísticas. Nesse sentido, dados e práticas governamentais se retroalimentam de forma que se torna impossível dizer o que é precedente ao que. Não seria o mundo do qual falam os dados e sobre o qual atuam as políticas de governo um efeito das próprias práticas nele implicadas?

É através de instrumentos biopolíticos de gestão da vida como dados e estatísticas que certas categorias passam a operar no mundo e que certos corpos passam a existir nele. Como nos mostra Fassin (2007) na descrição das intensas controvérsias que marcaram a epidemia de Aids na África do Sul, existem corpos que só aparecem para nós sob a forma de generalizações; dados despersonificados que inserem, mas também excluem o outro do nosso mundo. As estatísticas são, então, importantes instrumentos de intervenção política; se corporificam na forma de categorias, valores e práticas, e se inscrevem nos corpos na forma de registros e marcas biográficas, fazendo ecoar estigmas e desigualdades preexistentes. No Brasil, a COVID-19 faz ecoar as desigualdades nos corpos daquelas e daqueles que não puderam aderir ao isolamento social; nas experiências cotidianas das pessoas que não encontram em suas casas espaço seguro ou nas estratégias de sobrevivência dos que perderam suas principais fontes de renda. Mas essas histórias não são contadas, e quando o são, as narrativas são profundamente atravessadas pelo discurso biomédico de identificação de sintomas, tratamento e prevenção da propagação do vírus. A narrativa da COVID-19 consiste em uma narrativa da infecção, e pouco em uma narrativa da afecção, para usar os termos de Fassin (2007). 


\section{Práticas científicas e práticas estatais}

Ao mesmo tempo, a estatística como prática científica produz também dados que têm sido desconsiderados pelo Estado. Lembremos da PEC do Teto de 2016, nomeada Emenda Constitucional do Teto dos Gastos Públicos (e não dos investimentos), que limita os gastos do Estado durante 20 anos através de um "Novo Regime Fiscal”, que não é nada mais do que a tentativa de equilíbrio das contas públicas com base na lógica contabilística: mais investimentos, menos gastos - limitação que recai, sobretudo, nos repasses para a Saúde e a Educação. Durante o processo de discussão e avaliação da PEC no Congresso e no Senado, muitas estatísticas alternativas foram produzidas pela comunidade científica para avaliar os impactos dos cortes na saúde e educação públicas a longo prazo, mas essas estatísticas foram desconsideradas e só em 2019 o SUS deixou de receber 9 bilhões de reais por conta da emenda ${ }^{5}$.

Quando falamos de uma ciência de governo, é difícil delimitar os lugares de onde essas práticas vêm, já que elas podem brotar de comunidades científicas comprometidas, mas serem usadas para produzir efeitos muito distintos daqueles esperados. Apesar de por vezes compartilharem um mesmo estatuto epistemológico e, também, certas práticas de produção de conhecimento, tenho procurado entender de que maneira práticas científicas se tornam práticas estatais e que modulações sofrem nesse processo. Como é o caso do "design etnográfico" no laboratório de inovação em governo, essas práticas não passam isentas pelo empréstimo.

Seria possível dizer que aquilo que as difere de forma definitiva é o modo como essas ferramentas são motivadas por interesses distintos e, justamente por isso, acabam por produzir efeitos e narrativas diversas. Como nos mostra Asad (1994) em sua reflexão em torno da questão da representatividade para a antropologia e para as estatísticas, o que para nós parece ser incomensurável, já que o mundo do outro não pode ser compreendido sem distorções, se torna comensurável pela sistematização de dados. A mensurabilidade é uma das ferramentas que torna possível a produção a um só tempo de uma percepção de governo das incertezas e de um controle da percepção através da mobilização de uma "retórica do oficial" (BOURDIEU, 2007) ou da própria materialização desses modelos estatísticos no mundo por meio de programas de governo.

É em sua interação com a burocracia que esse aspecto da produção de dados fica ainda mais evidente. A capacidade das estatísticas em produzir mundos sociais é vista por Gupta (2012) em seu trabalho a respeito das políticas de desenvolvimento e combate à pobreza na Índia como efeito de suas relações intrínsecas com a produção de narrativas pelo Estado e sobre o Estado: as estatísticas operam como subsídio para as narrativas em prosa de relatórios e documentos, mas também criam suas próprias narrativas através de curvas que

\footnotetext{
5 "Saúde deixou de receber R\$9 bi em 2019 devido à regra do teto de gastos, mostra Tesouro Nacional". Fonte: O Globo. Página visitada em 24.04.2020.
} 
se tornarão comportamentos de grupos ou variações que se tornarão anomalias, por exemplo. É importante notar o que, nesse caso, também fica de fora dos dados: aquilo que não pode ser mensurado não consta nas estatísticas governamentais. A dor, a insegurança, o luto, escapam.

Se para as estatísticas científicas a amostra é o que há de mais importante na produção de dados, já que é imprescindível que ela tenha uma relação estreita de representatividade com aquilo sobre o qual pretende falar, para as estatísticas governamentais a produção de dados parece passar por outros lugares; lugares onde as experiências individuais são enumeradas, comparadas, equacionadas, para que soluções possam ser apresentadas aos fenômenos tornados legíveis. Ainda que essas soluções pareçam ser muitas vezes inefetivas, sua efetividade está, como sugere Gupta (2012), no próprio ato de produzir Estado enquanto unidade. É através das estatísticas que se produz coesão entre diferentes escalas estatais - do preenchimento de formulários pelas Secretarias Municipais e Estaduais de Saúde à divulgação de dados estatísticos nacionais pelo Ministério da Saúde, a narrativa sobre o Coronavírus produz também uma narrativa sobre o Estado.

A epidemia da COVID-19 e os embates em torno das melhores formas para se lidar com um cenário de crise sugerem algumas reflexões em torno da produção discursiva e técnica do Estado como um aglomerado de diferentes ideias e práticas em disputa, na qual a instituição dos fatos e dos procedimentos mais adequados depende do discurso das fantasias e ficções como modo de descredibilizar outras formas de ver e pensar, garantindo certo domínio no governo das incertezas, das probabilidades e dos fenômenos populacionais. A legitimação dos fatos se dá através da autoridade técnica da figura do especialista, lugar no qual os ministros e seus subordinados têm sido colocados, por vezes em oposição às autoridades técnicas das próprias comunidades científicas.

O discurso técnico busca, então, esterilizar as decisões políticas da própria política, um efeito ilusionista que confere legitimidade aos dados produzidos pelo Estado. Lewandowski (2019), em um artigo recente a respeito das práticas jurídicas do Supremo Tribunal Federal, fala do "fazer política sem deixar o mundo da política interferir na técnica do Direito”. Neste caso, seria possível falar de um fazer política nas sombras de um discurso técnico, justamente para não deixar que a política se sobressaia de modo que as relações que tornam certos dados legítimos se tornem visíveis. Trata-se de sustentar o que Hacking (1991) chama de uma incoerência histórica entre as condições prévias que tornam certos conceitos possíveis e os conceitos tornados possíveis apenas em razão dessas condições prévias.

Os dados produzidos durante a pandemia do Coronavírus nos mostram, então, os procedimentos mais ou menos homogêneos através dos quais a ciência de governo pensa, age e produz os seus próprios conhecimentos. Uma análise antropológica dessas estatísticas se propõe a falar não apenas daquilo que está sendo subnotificado ou supernotificado pelos 
dados. Não se trata apenas de exigir um número mais preciso ou mais fidedigno de casos e óbitos, mas de compreender o que esses dados nos informam a respeito de certas práticas que pretendem falar sobre o mundo a partir de um lugar imparcial e técnico.

\section{Referências bibliográficas}

ASAD, Talal. (1994). "Ethnographic representation, statistics and modern power". Social Research, Vol. 61, N.1, 1994, pp. 55-88.

BOURDIEU, Pierre. (2014). Sobre o Estado: cursos no Collège de France (1989-92). São Paulo: Companhia das Letras.

CALLON, Michel. (2020). "What does it mean to say that economics is performative?". Hal Archives, 2006. Disponível em: https://halshs.archives-ouvertes.fr/halshs00091596/document. Acesso em: 20 mai. 2020.

FASSIN, Didier. (2007). When bodies remember: experiences and politics of AIDS in South Africa. Berkeley: University of California Press.

FOUCAULT, Michel. (2008). Segurança, território, população. São Paulo: Martins Fontes.

GUPTA, Akhil. (2012). Red Tape: Bureaucracy, Structural Violence, and Poverty in India. Durham and London: Duke University Press.

HACKING, Ian. (1991). "How should we do the history of statistics?". In: BURCHELL, Graham; GORDON, Colin; MILLER, Peter. (Eds.). The Foucault effect: studies in governmentality. Chicago: University of Chicago Press, 1991.

LEWANDOWSKI, Andressa. (2019). Entre a política e a técnica: prática jurídica no Supremo Tribunal Federal brasileiro. Etnográfica, vol.23, n.2, p.299-322.

MORAWSKA, Catarina. (2018). "Luto e memória das Mães da Saudade de Peixinhos”. In: MARQUES; Ana Claudia Rocha Duarte; LEAL, Natacha (Orgs.). Alquimias do Parentesco: casas, gentes, papeis, territórios. Rio de Janeiro: Gramma; Terceiro Nome, 2018.

MORA WSKA, Catarina; RIBEIRO, Magda dos Santos. (2018). "Notas sobre as intersecções entre Estado, Ciência, Capitalismo: desafios etnográficos em torno da técnica e da política”. Revista de Antropologia da UFSCar-R@U, v. 10, n. 1, 2018.

ONG, Aihwa; COLLIER, Stephen (Eds). Global Assemblages: Technology, Politics, and Ethics as Anthropological Problems. Blackwell Publishing: 2005.

ROSE, Nikolas." Governing advanced liberal democracies”. In: ARADHANA, Sharma; GUPT, Akhil; (Eds.). The anthropology of the State: a reader. Wiley-Blackwell, 2006.

SEGATA, Jean. Cientistas Sociais e o coronavirus. Boletim Especial da ANPOCS, n.2, 23 de mar. de 2020. Disponível em: http://www.anpocs.org/index.php/cienciassociais/destaques/2325-boletim-semanal. Acesso em 20 mai. 2020. 
SENRA, Nelson de Castro. (2011). "O povo (sem senso?) em armas contra as medidas racionais do governo imperial brasileiro (1851-1852)”. In: (Org). Em Associação das Américas, as estatísticas públicas como objeto de estudo. Salvador: SEI.

STENGERS, Isabelle. (2002). A invenção das ciências modernas. São Paulo: Editora 34.

\section{sobre a autora}

\section{Barbara Gonçalves Moraes}

É mestranda do Programa de Pós-Graduação em Antropologia Social do Museu Nacional/UFRJ. Bacharel em Ciências Sociais pela Universidade Federal de São Carlos (UFSCar).

Recebido em 21/05/2020 Aceito para publicação em 31/07/2020 